\title{
BMJ Open Organised colorectal cancer screening in Lampang Province, Thailand: preliminary results from a pilot implementation programme
}

Thiravud Khuhaprema, ${ }^{1}$ Suleeporn Sangrajrang, ${ }^{1}$ Somkiat Lalitwongsa, ${ }^{2}$ Vanida Chokvanitphong, ${ }^{1}$ Tawarat Raunroadroong, ${ }^{2}$ Tawee Ratanachu-ek, ${ }^{3}$ Richard Muwonge, ${ }^{4}$ Eric Lucas, ${ }^{4}$ Christopher Wild, ${ }^{5}$ Rengaswamy Sankaranarayanan ${ }^{4}$

To cite: Khuhaprema T, Sangrajrang S, Lalitwongsa $\mathrm{S}$, et al. Organised colorectal cancer screening in Lampang Province, Thailand: preliminary results from a pilot implementation programme. BMJ Open 2014;4:e003671. doi:10.1136/bmjopen-2013003671

- Prepublication history and additional material for this paper is available online. To view these files please visit the journal online (http://dx.doi.org/10.1136/ bmjopen-2013-003671).

Received 26 July 2013 Revised 4 December 2013 Accepted 6 December 2013

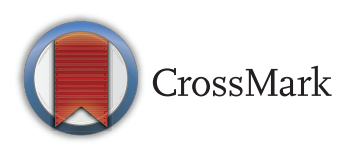

For numbered affiliations see end of article.

Correspondence to Dr Rengaswamy Sankaranarayanan; SankarR@iarc.fr

\section{ABSTRACT}

Objective: Colorectal cancer (CRC) is the third-most and fifth-most common cancer in men and women, in Thailand. The increasing CRC incidence and mortality can be reduced by screening and treating adenomas and early cancers. A pilot CRC screening programme using immunochemical faecal occult blood testing (FFOBT) and colonoscopy for test-positives were implemented through the routine Government Health Services in Lampang Province, to inform the acceptability, feasibility and scaling-up of screening in Thailand. This report describes the implementation, coverage and performance indicators of this project.

Design: A target population aged $50-65$ years was informed about and invited face to face to undergo CRC screening by community health workers (HWs). The HWs provided faecal sample collection kits and participants brought their samples to one of the primary health units or community hospitals where nurses performed iFOBT. iFOBT-positive persons were referred for colonoscopy at the Lampang cancer hospital, and endoscopic polypectomy/biopsies were performed according to the colonoscopic findings. Those with confirmed CRC received appropriate treatment.

Results: Of the 127301 target population, $62.9 \%$ were screened using iFOBT between April 2011 and November 2012. Participation was higher among women (67.8\%) than men $(57.8 \%)$ and lower in 50-54 year-old persons than in 60-65-year-olds. Of those screened, $873(1.1 \%)$ were found positive; positivity was higher in men (1.2\%) than in women (1.0\%). To date $627(72.0 \%)$ iFOBTpositive persons have had colonoscopy in which $3.7 \%$ had CRC and 30.6\% had adenomas.

Conclusions: The successful implementation of the pilot CRC screening with satisfactory process measures indicate the feasibility of scaling-up organised CRC screening through existing health services in Thailand.

\section{INTRODUCTION}

Colorectal cancer (CRC) is a major cancer in Thailand with age-standardised incidence rates of 12.9/100 000 in men and 9.2/100 000

\section{Strengths and limitations of this study}

- This pilot study documents the feasibility, acceptance and safety of colorectal cancer (CRC) screening in a lower-middle-income country.

- The study has been carried out in real-life conditions using the existing routine healthcare services, allowing a realistic and pragmatic assessment of the feasibility, sustenance and intermediate outcomes of colorectal screening in a lower-middle-income country.

- No information is provided on the extent of falsenegative tests and the impact of the intervention on CRC incidence and mortality due to lack of long-term follow-up of the study population at this instance. This information will be eventually generated by active and passive follow-up of the study population in future.

- The study did not include population aged between 66 and 74 years.

in women in 2005 and an incidence which is steadily increasing over time. ${ }^{1}$ Sedentary lifestyle, lack of physical activity, smoking, drinking alcohol, a high consumption of red and processed meats as well as a low consumption of whole grains, fibre, fruits and vegetables are associated with an elevated risk of CRC. Most CRCs occur in pre-existing adenomatous polyps; a small percentage of the colonic polyps may become cancerous and spread elsewhere. $^{2}$ This progression takes at least 10 years in most people. Early detection and removal of polyps in the colon and rectum may prevent the development of invasive CRC. ${ }^{3}$

Early detection and prevention of CRC through screening is an effective intervention to reduce the considerable human and financial costs. ${ }^{4}$ Tests considered for screening include variants of faecal occult blood tests (FOBTs), flexible sigmoidoscopy and colonoscopy. Of these, FOBTs are the most 
feasible, non-invasive, affordable and acceptable for population screening as they detect intermittent microscopic blood losses from early CRC to advanced adenomas. Chemical FOBT (cFOBT) not only uses guaiac to detect peroxidase in human blood, but also reacts to the peroxidase present in dietary constituents such as red meat, cruciferous vegetables and some fruits, while the recently developed immunochemical FOBT (iFOBT) uses an antigen-antibody reaction to specifically detect globin which, together with haeme, constitutes human haemoglobin. iFOBT is not subject to false-negative results in the presence of high-dose vitamin $\mathrm{C}$ supplements, which block the peroxidase reaction; since globin is degraded by digestive enzymes in the upper gastrointestinal tract, iFOBT is more specific for lower gastrointestinal bleeding, thus improving their specificity for colorectal neoplasia.

It has been shown in pooled analysis of four randomised controlled trials that annual or biennial screening with cFOBT reduced overall CRC mortality by $16 \%$ for those allocated to CRC screening and reduced CRC mortality by $25 \%$ for those attending at least one round of screening with cFOBT. ${ }^{4}$ The iFOBT provides a suitable and better alternative to $\mathrm{CFOBT}$ as a screening test due to its higher sensitivity, simplicity, ease of use and the fact that it does not require any dietary restriction..$^{5-8}$

CRC screening programmes are increasingly organised at regional and national levels in many countries. Programmes in countries such as Australia, Canada, Finland, France and the UK use either direct mail invitations or invitations initiated by general practitioners to target populations aged $50-65$ or 55-69 or 50-74 years. Programmes in Canada and Finland use cFOBT, whereas iFOBT is used in Korea and Japan. ${ }^{9-12}$ Although FOBT and colonoscopy are opportunistically provided in urban hospitals, there is no populationbased organised CRC screening programme in Thailand. The public health authorities in Thailand, faced with the increasing risk of CRC, due to the transition to westernised lifestyles with socioeconomic development, would like to take measures to reduce its incidence and deaths by primary prevention and screening.

Thailand has a well-developed public health services with an extensive primary care network well integrated with district, provincial hospitals and tertiary care centres such as several comprehensive regional cancer centres and advanced university hospitals. Four decades ago when Thailand was a low-income country, it invested early in healthcare and transportation infrastructure that has reached most remote rural communities and helped it to achieve healthcare at low costs, given the fact that $4.1 \%$ of its gross domestic product (GDP) was spent for health, a figure far lower than the $10 \%$ average in highincome countries. Thailand has been successful in training doctors, nurses, auxillary and paramedical health workers (HWs) and technicians in large numbers for its health system, with innovative distribution of human resources to rural areas. In addition, health volunteers recruited from local communities play important support, prevention and early detection roles, thereby enhancing community involvement. The entire Thai population is covered through a comprehensive healthcare package through universal health coverage (UHC) for financing an extensive range of preventive, diagnostic, treatment and follow-up care and hospitalisations due to any illness. ${ }^{13}$

In this context, a decision was made to implement a pilot CRC screening programme with iFOBT followed by full colonoscopy for test-positive persons using existing facilities and personnel in government health services in Lampang Province. This pilot study was implemented to assess the feasibility, acceptability, safety of CRC screening in urban and rural settings and to inform whether and how to introduce a nationwide, organised CRC screening programme through the existing public health services in a phased manner. Lampang Province was chosen to implement the pilot project, due to its representativeness of the wider Thai population in terms of demographic and socioeconomic profiles, a relatively high incidence rate of CRC $(18.7 / 100000$ in men and 14.4/100 000 in women $),{ }^{14}$ the availability of comprehensive cancer diagnosis, treatment and follow-up care facilities in general, and colonoscopy, histopathology and CRC treatment services in particular, at the Lampang provincial hospital (803 beds) and the Lampang Cancer Hospital (137 beds) and the existing population-based cancer registry that will help to evaluate the impact of the pilot intervention on CRC incidence and mortality in the province. We report the organisation, implementation, coverage and performance of the pilot CRC screening in this manuscript.

\section{MATERIAL AND METHODS}

\section{Project proposal development}

A detailed project proposal describing the background, project procedures, study questionnaires and forms to capture participant data and details of investigations, the project database, quality assurance methods and means of monitoring and evaluation were jointly developed between June 2010 and March 2011 by the National Cancer Institute (NCI), Bangkok, Thailand, and the provincial health authorities with technical assistance from the Screening Group of the International Agency for Research on Cancer (IARC) of the WHO, Lyon, France. Following the finalisation of the project proposal, its approval by national authorities and completion of training for the providers, screening started in April 2011 and recruitment of eligible participants was closed in November 2012.

\section{Target population and involved healthcare facilities and personnel}

All apparently healthy, ambulant men and women aged 50-65 years with no history of CRC and resident in Lampang Province were the target population for 
screening in the pilot project, totalling 127301 eligible participants, as identified from the National Statistics office and from the population registers with the health centres in the province. The Government healthcare infrastructure consisting of 154 primary care units (PCUs), 12 community hospitals (CHs), Lampang provincial hospital and Lampang Cancer Hospital and the doctors, nurses, HWs and technicians in these public facilities provided various services such as information dissemination, invitation, testing, diagnosis, treatment and follow-up care to the screening project. These tasks were assigned as additional responsibility to these facilities and personnel and no added financial incentives were provided to them for these added tasks. No additional workers were hired for this project. The screening programme was coordinated by the NCI and the provincial health authority and was technically supported by the IARC.

\section{Training for screening and colonoscopy providers}

The registered nurses, community HWs of the 154 PCUs and $12 \mathrm{CHs}$ of Lampang Province were trained on information dissemination on CRC screening, awareness creation, motivation of the target population and invitation of eligible persons to participate in CRC screening during a one-day session with a faculty from the NCI and provincial health authority. They were trained to explain to the participants how to collect the faecal specimen in the sample collection tube and bring it to the $\mathrm{PCU}$ or the $\mathrm{CH}$ within $3 \mathrm{~h}$ from collection for occult blood testing. The training also covered the performance and interpretation of the iFOBT test. Attractive pamphlets and posters in Thai language describing the prevention and early detection of CRC, the method of collecting the faecal samples, the iFOBT test procedure, colonoscopy and treatment of CRC were developed and printed by the Thai Health Services with technical support from the NCI and IARC. The HWs routinely visit all households under the jurisdiction of each PCU once in 6 months to provide preventive care. The eligible participants for CRC screening in this study were met, educated, invited and encouraged to participate in screening and the pamphlets and the faecal collection pots were distributed by HWs to eligible participants during these routine house visits. Family history of CRC among first-degree and second-degree relatives was enquired into during the house visits. The posters were prominently displayed in all healthcare facilities, educational institutions, public offices and public places.

Gastroenterologists and surgeons at the Lampang provincial hospital and the Lampang Cancer Hospital were reoriented and retrained in key aspects of colonoscopy to improve their hands-on colonoscopy/polyp excision/ biopsy skills in live sessions during 5 days. They were taught and evaluated by skilled gastroenterologists, with several years of experience in colonoscopy and endoscopic removal of polyps and mucosal resection of small lesions from the NCI and the Thai Association of
Gastrointestinal Endoscopy in live sessions under direct observation before the initiation of the programme.

\section{Screening invitation and organisation}

The existing healthcare infrastructure and personnel in the PCUs and the CHs were used to disseminate information, to invite and provide iFOBT and to refer those testing positive for colonoscopy. The HWs from the PCUs and CHs distributed a faecal sample collection kit to the eligible persons in the households under their jurisdiction as per a regular schedule and explained how to collect the specimen and when to bring the collected specimen to the PCU/CH for testing. The colonoscopy, histopathology and treatment services at the Lampang provincial hospital and the Lampang Cancer Hospital were used to diagnose and treat patients in the programme.

\section{Screening with iFOBT and referral}

All faecal samples were subjected to one-step iFOBT (Hemosure, EL Monte, USA) according to the manufacturer's instructions. The test was carried out at the $\mathrm{PCU} / \mathrm{CH}$ by the nurse in front of the participant. In less than $5 \mathrm{~min}$, a level of haemoglobin as low as $200 \mathrm{ng} / \mathrm{mL}$ can be detected by this test. A pink-rose band appearing in the ' $\mathrm{C}$ ' region and the ' $\mathrm{T}$ ' region of the test device indicates a positive iFOBT. A negative iFOBT is characterised by only one colour band in the ' $\mathrm{C}$ ' region. In this study, faecal material was assessed from one sample taken from each participant (1-day iFOBT). Verbal informed consent was obtained from all the participants before analysing the stool sample. The nurse at the $\mathrm{PCU} / \mathrm{CH}$ fixed an appointment for colonoscopy at the Lampang cancer hospital for iFOBT-positive persons and explained the precolonoscopy bowel preparation and the colonoscopy procedure in detail, provided a prescription for bowel cleansing and encouraged them to comply with the referral.

\section{Colonoscopy}

Colonoscopy was provided to iFOBT-positive individuals on scheduled days every week at the Lampang Regional Cancer Center. A second informed consent was obtained from people undergoing colonoscopy, biopsy and treatment. The outcome of colonoscopy was reported as normal, polyps, suspected cancer or invasive cancer. Polyps and small lesions were removed and subjected to histopathology. Large lesions were biopsied for histological assessment. Those diagnosed with CRC received further investigations for clinical staging and treatment as per the standard protocol developed in Thailand. The findings of colonoscopy, any severe adverse events within 30 days following colonoscopy (such as bleeding, perforation, administration of blood transfusion, hospitalisations for severe abdominal pain, paralytic ileus, cardiovascular events, hypotension, syncope, shock, dehydration, anaphylactic reactions, cardiorespiratory arrest, etc), histology, stage, treatment and 
follow-up assessment were recorded in a diagnosis and treatment form and were entered into the database.

\section{Data management, monitoring and evaluation}

Personal identification (name, age, address and citizen ID number), sociodemographic information, screening test result, results of colonoscopy and other investigations, treatment details and follow-up information were collected in specifically developed forms and entered in a multiuser programme database with inbuilt validation checks called CRCreg developed by the IARC. The database was continuously updated as the pilot project progressed. It is possible to link the screening programme and the cancer registry databases using the unique citizen ID numbers, which will enable the identification of false-negative cases and interval cancers.

The study database was analysed to document participant characteristics, participation rates for screening and test positivity rates by sex, age, the district of residence and the proportion of test-positive individuals complying with referral for colonoscopy, colonoscopy results, final diagnosis, stage of invasive cancer, treatment details and adverse events. Comparison of proportions was carried out using a two-sided test on the equality of proportions using large-sample statistics, which also gives exact $\mathrm{p}$ values. Assessment of the effect of patient characteristics on the attendance for colonoscopy was carried out using logistic regression analysis.

\section{RESULTS}

The flow chart of the programme organisation and procedures is shown in figure 1. All 154 PCUs and $12 \mathrm{CHs}$ $(100 \%)$ in the province participated in the project. Of the 127301 eligible participants (63274 men and 64027 women), 80012 (62.9\%; 36601 men and 43411 women) were enrolled. The distribution of sex, education, occupation and family history of CRC among the participants are given in table 1 . The mean age was 56.6 $(\mathrm{SD}=4.3)$ among women and $56.8 \quad(\mathrm{SD}=4.3)$ among men. More than $80 \%$ of the participants had only primary school education; three-fourths were involved in agriculture; and $0.7 \%$ had family history of CRC.

The overall participation rate for screening $(62.9 \%)$ was much higher in women $(67.8 \%, 95 \%$ CI $67.4 \%$ to $68.2 \%)$ than in men $(57.8 \%, 95 \%$ CI $57.5 \%$ to $58.2 \%$, table 2; $\mathrm{p}<0.001)$. Participation in screening varied between the 13 districts in the province: generally being higher in rural $(73.2 \%, 95 \%$ CI $72.9 \%$ to $73.5 \%)$ than in urban districts $(45.1 \%, 95 \%$ CI $44.6 \%$ to $45.5 \%$, table 2 ; $\mathrm{p}<0.001$ ), categorised as defined by the National Statistics Office based on demography, economy, educational, occupational and migration criteria. The highest iFOBT uptake was in the rural district of Theon $(86 \%$ in women and $73.4 \%$ in men) while the lowest participation was in the urban district of Mueang $(47.7 \%$ in women and $35.1 \%$ in men). Screening participation rates increased from $52.9 \%$ in those aged $50-54$ years to $78.9 \%$ among those aged $60-65$ years (table 3 ).

Using a cut-off faecal haemoglobin concentration of $200 \mathrm{ng} / \mathrm{mL}, 873$ of $80012(1.1 \%)$ participants were reported as positive on iFOBT. The iFOBT positivity rate was slightly higher in men $(1.2 \%)$ than in women $(1.0 \%, \mathrm{p}=0.001$; table 2$)$. Test positivity rate increased from $0.8 \%$ in those aged $50-54$ years to $1.5 \%$ in those aged $60-65$ years (table 2 ).

As of 21 February 2013, 627 (71.8\%) iFOBT-positive persons had colonoscopy; no serious adverse event was reported following colonoscopy. On colonoscopy, 206 were found to have polyps and cancer was suspected in 27 persons (table 3). Polyps were excised and biopsies were directed in growths. On histological examination of excised polyps, adenoma was confirmed in 187 persons (table 3). CRC was histologically confirmed in 23 persons $(3.7 \%)$. The detection rate of histologically confirmed CRC was 2.9/10 000 screened persons and that of adenomatous polyp was 23.4/10000 screened persons. CRC and adenomas were detected in $3.6 \%$ and $29.8 \%$, respectively, of iFOBT-positive individuals who had colonoscopy.

Among the 187 persons with histologically confirmed adenomatous polyps, $75(40.1 \%)$ had advanced adenoma. Advanced adenoma denotes adenomatous polyps having one or more of the following features: $>10 \mathrm{~mm}$ in diameter, high-grade dysplasia and significant villous histology $(>25 \%)$. The stage-distribution of the detected invasive cancers was as follows: 2 stage I, 12 stage II, 7 stage III and 2 missing stage information. Compliance for colonoscopy referral was lower among individuals living in urban compared with rural areas and in those with relatively high compared with those with low monthly family incomes (table 4).

\section{DISCUSSION}

Among the CRC screening approaches in people at average risk (persons aged 50-74 years), annual or biennial FOBT followed by colonoscopy triage of screenpositive individuals is the most widely used strategy due to its low cost, feasibility, safety and non-invasiveness. Significant reduction in CRC incidence and mortality following cFOBT screening has been shown in four randomised controlled trials. ${ }^{4}$ This evidence, the fact that iFOBT is a better alternative to cFOBT and the declines in CRC mortality following widespread CRC screening in Japan, South Korea, Hong Kong and Singapore, despite increasing CRC incidence rates, ${ }^{15}$ and in other high-income countries, ${ }^{16}{ }^{17}$ supported our decision to implement a pilot project based on 1-day iFOBT screening integrated into the routine public health services in Lampang province in Thailand.

Since CRC screening is a major undertaking and integrating a cancer screening programme into routine government health services in low-middle income countries has its own complexities and challenges, it was decided to 


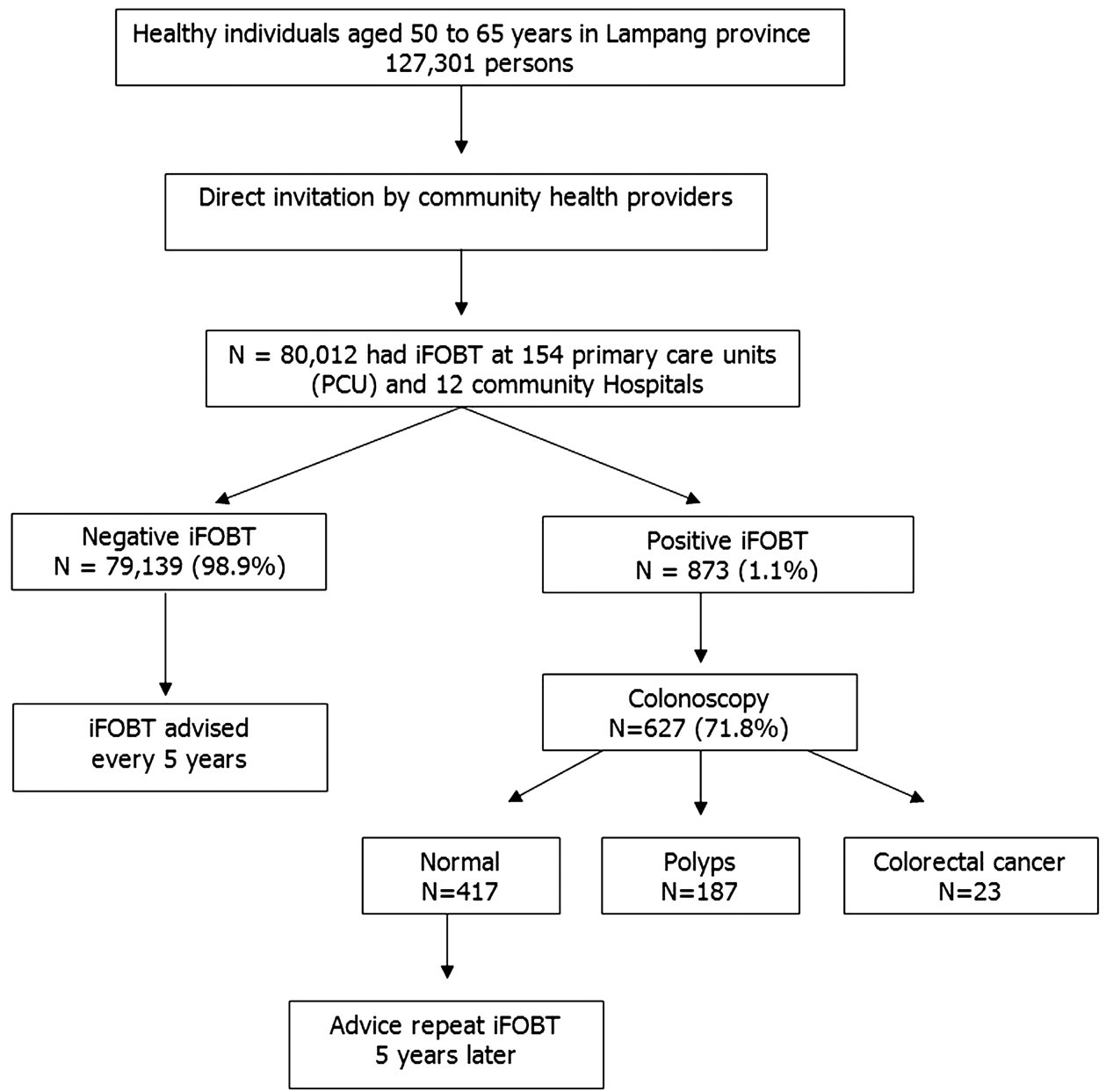

Figure 1 A schematic diagram of the pilot colorectal cancer screening programme in Lampang province, Thailand. iFOBT, immunochemical faecal occult blood testing.

pilot its introduction in one of the provinces of Thailand which already has a population-based cancer registry. In high-income countries, large-scale population-based organised CRC screening has been preceded by well-planned pilot introductions to evaluate the feasibility, practicality and acceptability of introducing a population screening programme with biennial FOBT in government health services (table 5). ${ }^{18-21}$ The UK CRC screening pilot study was launched in 2000 in England and Scotland, which reported an FOBT uptake rate of $57 \%$ and a CRC detection rate of $1.62 / 1000$ screened (table 5). ${ }^{18}{ }^{19}$ In the Australian pilot CRC screening project, 56907 women aged 55-74 years were invited to iFOBT screening during November 2002 to June 2004. Of them, 25840 (45.4\%) persons participated, 25688 correctly completed iFOBT screening and 2317 (9\%) persons were positive on iFOBT. The pilot project detected 176 persons with advanced adenoma and 67 with suspected cancer, yielding a positive predictive value of $19.2 \%$ (table 5 ); the estimated cost per additional life year saved in the Australian pilot project was $\$$ A24 000. ${ }^{21}$ In the Finnish pilot project, the participation rate was $71 \%$ among 52994 invited persons and $2.1 \%$ of the participants were positive on FOBT and $51.8 \%$ of those who underwent colonoscopy were detected with adenomas or suspected cancer. ${ }^{20}$ The national expansion of CRC screening in the UK, Australia and Finland following the pilot studies was phased over 6 years.

The results on participation and detection rates of colorectal neoplasia in our pilot project in Lampang are consistent with findings from pilot (table 5) and national programmes elsewhere. For example, the participation rate of eligible participants in our Thai study was similar to rates reported from pilot demonstration projects in the UK (57\%), Haut-Rhin, France $(55 \%)$ and in Finland $(71 \%)$ and in service programmes in the UK $(54 \%)^{182022} 23$ and was higher than those reported from the Australian pilot project (45.4\%), a systematic review of participation in CRC screening programmes $(42 \%)$ and from the national CRC screening programmes in Australia (35\%), ${ }^{24}$ South Korea $(<25 \%)$ and Croatia $(10 \%) .^{11} 212526$ Our results confirm that the use of primary HWs outreach to promote and provide CRC screening through existing Government health services is feasible in Thailand.

A higher uptake of iFOBT was observed among women and in older age groups in our programme. 
Table 1 Characteristic of participants in the Lampang pilot colorectal cancer screening project

\begin{tabular}{|c|c|c|}
\hline Characteristics & Number & Per cent \\
\hline Screened & 80012 & \\
\hline \multicolumn{3}{|l|}{ Sex } \\
\hline Men & 36601 & 45.7 \\
\hline Women & 43411 & 54.3 \\
\hline \multicolumn{3}{|l|}{ Age (in years) } \\
\hline $50-54$ & 28956 & 36.2 \\
\hline $55-59$ & 27825 & 34.8 \\
\hline $60-65$ & 23231 & 29.0 \\
\hline \multicolumn{3}{|l|}{ Education } \\
\hline None & 6192 & 7.7 \\
\hline Primary & 66583 & 83.2 \\
\hline Secondary & 5208 & 6.5 \\
\hline College/university & 2028 & 2.5 \\
\hline \multicolumn{3}{|l|}{ Occupation } \\
\hline Agriculture & 57266 & 75.8 \\
\hline Manual labour & 11381 & 15.1 \\
\hline Support/service & 4718 & 6.2 \\
\hline Crafts/machinery & 371 & 0.5 \\
\hline \multicolumn{3}{|c|}{ Family income in Thai Bahts per month (US $\$ 1=30$ Bahts) } \\
\hline$<5000$ & 44940 & 58.4 \\
\hline $5000-10000$ & 26463 & 34.4 \\
\hline$>10000$ & 5533 & 7.2 \\
\hline \multicolumn{3}{|c|}{$\begin{array}{l}\text { Colorectal cancer in first-degree and second-degree } \\
\text { relatives }\end{array}$} \\
\hline Yes & 552 & 0.7 \\
\hline No & 72971 & 91.2 \\
\hline Unknown & 6489 & 8.1 \\
\hline \multicolumn{3}{|l|}{ Setting } \\
\hline Rural & 58873 & 73.6 \\
\hline Urban & 21139 & 26.4 \\
\hline \multicolumn{3}{|l|}{ District } \\
\hline Mueang (U) & 13016 & 16.3 \\
\hline Mae Moh (U) & 2772 & 3.5 \\
\hline Koh Kha (U) & 5351 & 6.7 \\
\hline Soem Ngam (R) & 3747 & 4.7 \\
\hline Wang Nua (R) & 5962 & 7.5 \\
\hline Chae Hom (R) & 6474 & 8.1 \\
\hline $\operatorname{Ngao}(R)$ & 7489 & 9.4 \\
\hline Thoen $(\mathrm{R})$ & 8486 & 10.6 \\
\hline Mae Phrik (R) & 2523 & 3.2 \\
\hline Mae Tha $(R)$ & 9025 & 11.3 \\
\hline Sop Prap (R) & 3977 & 5.0 \\
\hline Hang Chat (R) & 6447 & 8.1 \\
\hline Mueang Pan (R) & 4743 & 5.9 \\
\hline
\end{tabular}

A similar observation has been reported from CRC screening programmes in other countries. ${ }^{11} 182023-2527$ We observed a higher uptake of iFOBT screening in rural populations than in urban populations of Lampang province. Information on CRC screening and invitations for iFOBT screening in rural districts were mostly delivered to the target population by direct person-to-person contact and face-to-face communication, while in urban areas the information on the programme was predominantly delivered through poster advertisements due to the challenges in face-to-face contacts. The proportion of households visited was much higher in rural areas than in urban areas, where the sample collection kits were mostly collected by the eligible individuals during their routine and opportunistic visits to the health centres or $\mathrm{CHs}$ for routine health check-ups for early detection of diabetes, hypertension and helminthiasis and for other medical problems. Unfortunately, we could not exactly quantify the proportion of participation from home visits or by visits to the PCUs/CHs as this was not documented in the database. The higher screening uptake in rural populations than in urban areas suggests that more direct person-to-person contacts and personalised invitations and personalised delivery of collection kits improved the participation. A personalised approach to participant recruitment has also been reportedly associated with a higher uptake of CRC screening in other settings. ${ }^{26} \mathrm{~A}$ higher participation in rural populations than in urban and metropolitan populations has been reported from other countries as well. ${ }^{26}{ }^{28}$ Higher participation for colonoscopy among the low-income and rural population reflects the faith and dependence of the socioeconomically weaker sections on public health services than those with higher incomes and living in urban areas.

The overall iFOBT positivity rate in our pilot project was in the lower range of test positivity rates reported from high-risk, high-income countries. FOBT testpositive rates ranged from $2.1 \%$ to $9 \%$ in high-risk, highincome countries. ${ }^{11} 19-21242529-31$ Our results show that positivity rate in men $(1.2 \%)$ was slightly higher than in women (1\%), which is consistent with a higher CRC incidence in men (14.7/100 000 men) than in women (10.1/100 000 women) in Lampang province. A higher test positivity rate in men than in women has also been reported in other settings. ${ }^{18-21} 242930$

FOBT screening for CRC is effective only when a high proportion of those with a positive result attend further full colonoscopy diagnostic evaluation of the colon. Two-thirds of test-positive persons complied with referral for colonoscopy in our programme, which is within the range of adherence to colonoscopy referrals in highincome countries. In many national programmes, compliance of test-positive participants to colonoscopy ranged between $38 \%$ and $88 \% .{ }^{11} 23-253233$ There was no serious adverse event following colonoscopy in our programme. The risks of serious adverse events such as perforation, haemorrhage, peritonitis and acute diverticulitis following colonoscopy performed as part of CRC screening are low, but increase with age and following polypectomy; the rate of adverse events reportedly varied between 3 and $6 / 1000$ colonoscopies performed. ${ }^{34}$ The value of short and intensive retraining and reorientation courses for colonoscopists of varying experience in achieving high standards has been well established. ${ }^{35}$ Teaching practical hands-on skills in short intensive reorientation sessions to our programme gastroenterologists and assessment of their performance 
Table 2 Total eligible participants, screened eligible participants and test-positive frequencies by sex, age and districts in Lampang province, Thailand, 2011-2012

\begin{tabular}{|c|c|c|c|c|c|c|c|c|c|}
\hline & \multicolumn{3}{|l|}{ Men } & \multicolumn{3}{|l|}{ Women } & \multicolumn{3}{|l|}{ Overall } \\
\hline & $\begin{array}{l}\text { Eligible } \\
\text { persons }\end{array}$ & $\begin{array}{l}\text { Number } \\
\text { screened with } \\
\text { iFOBT (\%) } \\
\end{array}$ & $\begin{array}{l}\text { Number } \\
\text { screen } \\
\text { positive (\%) }\end{array}$ & $\begin{array}{l}\text { Eligible } \\
\text { persons }\end{array}$ & $\begin{array}{l}\text { Number } \\
\text { screened with } \\
\text { iFOBT (\%) } \\
\end{array}$ & $\begin{array}{l}\text { Number } \\
\text { screen } \\
\text { positive (\%) }\end{array}$ & $\begin{array}{l}\text { Eligible } \\
\text { persons }\end{array}$ & $\begin{array}{l}\text { Number } \\
\text { screened with } \\
\text { iFOBT (\%) }\end{array}$ & $\begin{array}{l}\text { Number } \\
\text { screen } \\
\text { positive (\%) }\end{array}$ \\
\hline Overall & 63274 & 36601 (57.8) & 447 (1.2) & 64027 & $43411(67.8)$ & $426(1.0)$ & 127301 & 80012 (62.9) & $873(1.1)$ \\
\hline \multicolumn{10}{|l|}{ Sex } \\
\hline Men & 63274 & 36601 (57.8) & 447 (1.2) & & & & 63274 & 36601 (57.8) & 447 (1.2) \\
\hline Women & & & & 64027 & $43411(67.8)$ & $426(1.0)$ & 64027 & 43411 (67.8) & $426(1.0)$ \\
\hline p Value & & & & & & & & $<0.001$ & 0.001 \\
\hline \multicolumn{10}{|l|}{ Age (in years) } \\
\hline $50-54$ & 27148 & 12927 (47.6) & $106(0.8)$ & 27597 & $16029(58.1)$ & $131(0.8)$ & 54745 & 28956 (52.9) & $237(0.8)$ \\
\hline $55-59$ & 21328 & 12711 (59.6) & $146(1.1)$ & 21777 & $15114(69.4)$ & $130(0.9)$ & 43105 & 27825 (64.6) & $276(1.0)$ \\
\hline 60-65 & 14798 & $10963(74.1)$ & $195(1.8)$ & 14653 & 12268 (83.7) & 165 (1.3) & 29451 & 23231 (78.9) & 360 (1.5) \\
\hline \multicolumn{10}{|l|}{ Setting } \\
\hline Rural & 40289 & 27692 (68.7) & 317 (1.1) & 40108 & 31181 (77.7) & $295(0.9)$ & 80397 & $58873(73.2)$ & $612(1.0)$ \\
\hline Urban & 22985 & 8909 (38.8) & $130(1.5)$ & 23919 & $12230(51.1)$ & $131(1.1)$ & 46904 & $21139(45.1)$ & 261 (1.2) \\
\hline p Value & & & & & & & & $<0.001$ & 0.019 \\
\hline \multicolumn{10}{|l|}{ District } \\
\hline Mueang (U) & 15188 & 5327 (35.1) & $60(1.1)$ & 16127 & 7689 (47.7) & $64(0.8)$ & 31315 & $13016(41.6)$ & $124(1.0)$ \\
\hline Mae Moh (U) & 2999 & 1300 (43.3) & $30(2.3)$ & 2690 & $1472(54.7)$ & 24 (1.6) & 5689 & 2772 (48.7) & 54 (1.9) \\
\hline Koh Kha (U) & 4798 & $2282(47.6)$ & $40(1.8)$ & 5102 & 3069 (60.2) & $43(1.4)$ & 9900 & $5351(54.1)$ & $83(1.6)$ \\
\hline Soem Ngam (R) & 2838 & 1757 (61.9) & $16(0.9)$ & 2581 & $1990(77.1)$ & $9(0.5)$ & 5419 & 3747 (69.1) & $25(0.7)$ \\
\hline Wang Nua $(\mathrm{R})$ & 4712 & $2988(63.4)$ & $46(1.5)$ & 4429 & $2974(67.1)$ & $51(1.7)$ & 9141 & $5962(65.2)$ & 97 (1.6) \\
\hline Chae Hom (R) & 4324 & 3123 (72.2) & $42(1.3)$ & 4385 & 3351 (76.4) & $38(1.1)$ & 8709 & $6474(74.3)$ & $80(1.2)$ \\
\hline $\operatorname{Ngao}(R)$ & 5603 & 3642 (65.0) & $18(0.5)$ & 5289 & 3847 (72.7) & $22(0.6)$ & 10892 & 7489 (68.8) & $40(0.5)$ \\
\hline Thoen $(\mathrm{R})$ & 5196 & 3814 (73.4) & $17(0.4)$ & 5431 & $4672(86.0)$ & $25(0.5)$ & 10627 & 8486 (79.9) & $42(0.5)$ \\
\hline Mae Phrik (R) & 1490 & 1087 (73.0) & $11(1.0)$ & 1683 & 1436 (85.3) & $10(0.7)$ & 3173 & $2523(79.5)$ & $21(0.8)$ \\
\hline Mae Tha $(\mathrm{R})$ & 5970 & $4161(69.7)$ & $61(1.5)$ & 6030 & $4864(80.7)$ & $45(0.9)$ & 12000 & 9025 (75.2) & $106(1.2)$ \\
\hline Sop Prap (R) & 2946 & 1876 (63.7) & $29(1.5)$ & 2993 & 2101 (70.2) & $16(0.8)$ & 5939 & 3977 (67.0) & $45(1.1)$ \\
\hline Hang Chat (R) & 4009 & $2991(74.6)$ & $41(1.4)$ & 4206 & 3456 (82.2) & $42(1.2)$ & 8215 & 6447 (78.5) & $83(1.3)$ \\
\hline Mueang Pan (R) & 3201 & $2253(70.4)$ & $36(1.6)$ & 3081 & $2490(80.8)$ & $37(1.5)$ & 6282 & $4743(75.5)$ & $73(1.5)$ \\
\hline
\end{tabular}

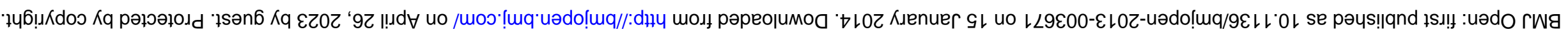


Table 3 Colonoscopy attendance, results and final diagnosis by sex

\begin{tabular}{|c|c|c|c|}
\hline & Men & Women & Total \\
\hline Number screened with iFOBT & 36601 & 43411 & 80012 \\
\hline Number screen positive (\%) & $447(1.2)$ & $426(1.0)$ & $873(1.1)$ \\
\hline Number attended colonoscopy referral (\%) & $319(71.4)$ & $308(72.3)$ & $627(71.8)$ \\
\hline \multicolumn{4}{|l|}{ Colonoscopy result (per 1000 screened) } \\
\hline Normal & 165 & 215 & 380 \\
\hline Polyp & $133(3.6)$ & $73(1.7)$ & $206(2.6)$ \\
\hline Suspected cancer & $16(0.4)$ & $11(0.3)$ & $27(0.3)$ \\
\hline Inadequate/unknown & 5 & 9 & 14 \\
\hline \multicolumn{4}{|l|}{ Final diagnosis (per 1000 screened) } \\
\hline Normal & 158 & 206 & 364 \\
\hline Inflammatory bowel disease & $5(0.1)$ & $2(0.0)$ & $7(0.1)$ \\
\hline Adenomatous polyp & $12(0.3)$ & $9(0.2)$ & $21(0.3)$ \\
\hline Adenomatous polyp with dysplasia & $108(3.0)$ & $51(1.2)$ & $159(2.0)$ \\
\hline Hyperplastic polyp & $4(0.1)$ & $1(0.0)$ & $5(0.1)$ \\
\hline Colitis & $4(0.1)$ & $6(0.1)$ & $10(0.1)$ \\
\hline Adenocarcinoma in situ & $3(0.1)$ & $4(0.1)$ & $7(0.1)$ \\
\hline Colorectal cancer & $13(0.4)$ & $10(0.2)$ & $23(0.3)$ \\
\hline Other & $11(0.3)$ & $18(0.4)$ & $29(0.4)$ \\
\hline Unknown & $1(0.0)$ & $1(0.0)$ & $2(0.0)$ \\
\hline
\end{tabular}

and competency in key aspects of colonoscopy by direct observation in live case sessions by experienced colonoscopists were valuable in ensuring the high-quality colonoscopy services in this programme. Based on our experience in this pilot project, we have developed a beginner's manual for colonoscopy for use in lowincome and middle-income countries.

Test-positive rate, CRC and adenomatous polyp detection rates per 1000 screened persons in our programme were lower than those reported from high-risk countries; however, the detection frequencies of the CRC and polyps as a proportion of iFOBT-positive persons $(2.6 \%$ for CRC and $21.4 \%$ for adenoma) and of those receiving colonoscopy (3.7\% for CRC and $29.8 \%$ for adenoma) are within the range reported (1.9-7\% for CRC and 20$43 \%$ for adenoma) from high-incidence countries, indicating the high quality of interventions in our pilot programme. ${ }^{18-21} 3132$ The low test positive and detection rates as a proportion of screened participants is not surprising given the comparatively low-incidence rates of CRC in Thailand as compared with high-incidence countries. ${ }^{1} 1436$

Most CRCs develop from adenomas, among which 'advanced' adenomas are considered to be the clinically relevant precursors. Among the adenomatous polyps, advanced adenoma is considered to be the most valid neoplastic surrogate marker for present and future CRC risk, and detecting advanced adenomas is a major focus in CRC screening. A high detection rate of advanced adenoma as compared with the more common, but less clinically significant small adenomas, is an important target of CRC screening and an indicator of high screening efficacy. ${ }^{37}$ It has been shown that the cumulative risk of malignancy in advanced polyps ranges between $25 \%$ and $45 \%$ in persons aged 55 years and above. ${ }^{38}$ Thus, advanced adenomas may be considered as surrogate for CRC. In our pilot project, two-fifths of detected adenomas were advanced adenoma. Two-thirds of CRC detected in our pilot project was in early stages. The high detection rate of advanced adenoma and early detection of CRC could have a higher impact on future CRC incidence and mortality in this pilot cohort.

While FOBT screening is repeated annually or biennially in high-risk countries, we have decided to repeat CRC screening once in 5 years in our pilot project and in Thailand when CRC screening is scaled up nationally, in view of the comparatively low CRC incidence. From a practical and sustainable perspective, particularly from the aspect of providing high-quality colonoscopy services, performing iFOBT screening once in 5 years is an attractive option given the level of development of healthcare infrastructure. The national scale-up of screening following the pilot project in Australia since 2006 occurs in a phased manner. ${ }^{39}$ It introduced National Bowel Cancer Screening Programme (NBCSP) in 2006 as one-off test for those turning 55 and 65 years, and testing for 50-year olds was added in 2008 and for 60-year olds in 2013; testing for 70-year olds will be added in 2015. It would then progressively shift to two yearly screening of all Australians aged 50-74 years from 2017 to 2018. Thus, a full-scale national scale-up in Australia will take 13 years from introduction. ${ }^{39}$ In Thailand, as we phase out the scale-up over several years, the performance of screening, particularly falsenegative rates and interval cancers, needs to be carefully assessed and the need for appropriate mid-course corrections for this policy should be promptly addressed as the programme evolves. Based on the preliminary 
Table 4 Colonoscopy attendance among screen positives by patient characteristics

\begin{tabular}{|c|c|c|c|c|}
\hline Characteristics & $\begin{array}{l}\text { Number } \\
\text { screen positive }\end{array}$ & $\begin{array}{l}\text { Number attended } \\
\text { colonoscopy clinic (\%) }\end{array}$ & Adjusted* OR $(95 \% \mathrm{Cl})$ & p Value \\
\hline Participants & 873 & $627(71.8)$ & & \\
\hline \multicolumn{5}{|l|}{ Sex } \\
\hline Men & 447 & $319(71.4)$ & 1.0 & \\
\hline Women & 426 & 308 (72.3) & $1.1(0.8$ to 1.5$)$ & 0.534 \\
\hline \multicolumn{5}{|l|}{ Age (in years) } \\
\hline $50-54$ & 237 & $177(74.7)$ & 1.0 & \\
\hline $55-59$ & 276 & $196(71.0)$ & 0.8 (0.5 to 1.3$)$ & 0.355 \\
\hline 60-65 & 360 & $254(70.6)$ & $0.8(0.5$ to 1.1$)$ & 0.186 \\
\hline \multicolumn{5}{|l|}{ Education } \\
\hline None & 97 & 73 (75.3) & 1.0 & \\
\hline Primary & 704 & $504(71.6)$ & 0.7 (0.4 to 1.3$)$ & 0.301 \\
\hline Secondary & 48 & $34(70.8)$ & 0.9 (0.4 to 2.4$)$ & 0.881 \\
\hline College/university & 24 & $16(66.7)$ & 0.6 (0.1 to 2.8$)$ & 0.556 \\
\hline \multicolumn{5}{|l|}{ Occupation } \\
\hline Agriculture & 632 & $474(75.0)$ & 1.0 & \\
\hline Managerial/professional & 22 & 15 (68.2) & $0.8(0.2$ to 3.5$)$ & 0.787 \\
\hline Support/service & 54 & $34(63.0)$ & 0.7 (0.4 to 1.2$)$ & 0.174 \\
\hline Crafts/machinery & 4 & $3(75.0)$ & $1.0(0.1$ to 10.9$)$ & 0.989 \\
\hline Manual labour & 95 & $60(63.2)$ & $0.7(0.4$ to 1.1$)$ & 0.097 \\
\hline \multicolumn{5}{|l|}{ Family income } \\
\hline$<5000$ & 531 & $399(75.1)$ & 1.0 & \\
\hline $5000-10000$ & 254 & $166(65.4)$ & $0.6(0.4$ to 0.9$)$ & 0.007 \\
\hline$>10000$ & 59 & 42 (71.2) & $0.9(0.4$ to 2.1$)$ & 0.887 \\
\hline \multicolumn{5}{|c|}{ Family history of colorectal cancer } \\
\hline Yes & 19 & $15(78.9)$ & 1.0 & \\
\hline No & 774 & $551(71.2)$ & 0.9 (0.3 to 2.9$)$ & 0.827 \\
\hline Unknown & 80 & 61 (76.3) & $1.1(0.3$ to 4.4$)$ & 0.846 \\
\hline \multicolumn{5}{|l|}{ Setting } \\
\hline Rural & 612 & $460(75.2)$ & 1.0 & \\
\hline Urban & 261 & $167(64.0)$ & $0.7(0.5$ to 1.0$)$ & 0.043 \\
\hline \multicolumn{5}{|l|}{ District } \\
\hline Mueang (U) & 124 & $72(58.1)$ & 1.0 & \\
\hline Mae Moh (U) & 54 & 39 (72.2) & 2.1 (0.9 to 4.6$)$ & 0.070 \\
\hline Koh Kha (U) & 83 & $56(67.5)$ & 1.5 (0.8 to 2.9$)$ & 0.225 \\
\hline Soem Ngam (R) & 25 & 21 (84.0) & 1.8 (0.4 to 7.7$)$ & 0.417 \\
\hline Wang Nua $(\mathrm{R})$ & 97 & $68(70.1)$ & 1.4 (0.7 to 2.7$)$ & 0.296 \\
\hline Chae Hom (R) & 80 & $63(78.8)$ & 2.0 (1.0 to 4.1$)$ & 0.062 \\
\hline $\operatorname{Ngao}(R)$ & 40 & $29(72.5)$ & 1.6 (0.7 to 3.8$)$ & 0.267 \\
\hline Thoen $(\mathrm{R})$ & 42 & $30(71.4)$ & 2.0 (0.8 to 4.6$)$ & 0.119 \\
\hline Mae Phrik (R) & 21 & $18(85.7)$ & $3.2(0.9$ to 12.1$)$ & 0.084 \\
\hline Mae Tha $(R)$ & 106 & $84(79.2)$ & 2.5 (1.3 to 4.8$)$ & 0.007 \\
\hline Sop Prap (R) & 45 & 31 (68.9) & 1.4 (0.6 to 3.2$)$ & 0.462 \\
\hline Hang Chat $(\mathrm{R})$ & 83 & 63 (75.9) & $3.2(1.5$ to 6.8$)$ & 0.003 \\
\hline Mueang Pan (R) & 73 & $53(72.6)$ & 1.6 (0.8 to 3.2$)$ & 0.185 \\
\hline
\end{tabular}

findings from our pilot study, we are conducting a formal cost-effectiveness analysis in collaboration with the Health Intervention and Technology Assessment Programme of the Thailand Government to determine the costs of all services provided along the screening pathway to estimate screening cost-effectiveness and funding required for the national programme.

A current limitation of our study is that it describes the process measures and intermediate outcomes such as adenoma detection rates and stage distribution of screen-detected CRCs but no information is available on the extent of false-negative tests and the impact of the intervention on CRC incidence and mortality due to lack of long-term follow-up of the study population at this instance. This information will be eventually generated by the active and passive follow-up of the study population in future. Another limitation is that people aged $66-75$ years were not included; however, this is 
Table 5 Comparison of pilot colorectal cancer screening projects in Thailand, Australia and the UK

\begin{tabular}{|c|c|c|c|}
\hline Criteria & Thailand & Australia $^{21}$ & $\mathrm{UK}^{18}$ \\
\hline Period & 2011-2012 & 2002-2004 & 2000-2003 \\
\hline Screening test used & iFOBT & iFOBT & gFOBT \\
\hline Targeted age group (years) & $50-65$ & $55-74$ & $50-69$ \\
\hline Target population, $\mathrm{n}$ & 127301 & 56907 & 478250 \\
\hline Individuals screened, n (\%*) & 80012 (62.9) & $25840(45.4)$ & $271646(56.8)$ \\
\hline Individuals screen positive, $\mathrm{n}(\% \dagger)$ & $873(1.1)$ & $2308(8.9)$ & $5050(1.9)$ \\
\hline Colonoscopy performed, n (\% & $627(71.8)$ & $1265(54.8)$ & $4116(81.5)$ \\
\hline Adenoma detected, $\mathrm{n}(\% \S)$ & 187 (29.8) & $251(19.8)$ & $1388(33.7)$ \\
\hline Advanced adenoma, n (\%§) & $75(12.0)$ & $176(13.9)$ & - \\
\hline Colorectal cancer detected, n (\%§) & $23(3.7)$ & $67(5.3)$ & $552(13.4)$ \\
\hline Stage I and II colorectal cancer, n (\%ף) & $14(60.9)$ & - & $345(62.5)$ \\
\hline Colorectal cancer detection rate per 100000 screened & 28.7 & 259.3 & 203.2 \\
\hline $\begin{array}{l}\text { *Based on target population. } \\
\text { †Based on individuals screened. } \\
\text { †Based on individuals screen positive. } \\
\text { §Based on colonoscopy performed. } \\
\text { १Based on colorectal cancer detected. }\end{array}$ & th & & \\
\hline
\end{tabular}

unlikely to have a major implication in any future scaling-up of screening for this age group. On the other hand, a major strength is that the study reflects the reallife conditions and has been conducted using the existing routine healthcare services, which allows a realistic assessment of the feasibility of colorectal screening in a middle-income country. The fact that Thailand has developed an equitably accessible healthcare system with UHC and has experienced an inclusive socioeconomic progress covering all regions of the country suggests that the pilot experience in Lampang can be translated to the national population in due course. However, additional specific measures need to evolve by qualitative studies to ensure adequate participation in urban areas.

In addition to the specific application of these findings to the further development of a CRC screening programme in Thailand, the approach taken here illustrates some more general principles of note. First, middle or high human development index countries experiencing the cancer transition ${ }^{40}$ may pre-empt projected increases in cancers of certain organs by implementing prevention or early detection before those increases become manifest. Second, the type of implementation research reported here is well suited to low-income and middle-income countries given the direct relevance to cancer control and the relatively low additional cost of integrating a research component into national public health programmes. Third, the research project converges with capacity building, in this case through training of different categories of health professionals, so that the programme once implemented benefits from the developments required by the research itself.

In conclusion, our results indicate the acceptability, feasibility, organisation and implementation of CRC screening in the general population setting in Thailand and the feasibility of integrating the programme within the existing public health services. Although we are encouraged by the high participation rates from rural districts, the participation in urban areas needs to be improved by appropriate invitation logistics. It is our belief that no associated direct financial costs to the eligible individuals due to $\mathrm{UHC}$ and the appropriate organisation, availability and access to services within the programme have minimised the barriers to access for socioeconomically disadvantaged populations. The implementation of the pilot programme has been successful as measured by the process measures of coverage, performance of the screening test, colonoscopy and removal of colonoscopically detected polyps, provision of histopathology services and detection and treatment of CRC in early clinical stages to which have met the criteria of a successful public health programme.

\section{Author affiliations}

${ }^{1}$ National Cancer Institute, Bangkok, Thailand

${ }^{2}$ Lampang Cancer Hospital, Lampang, Thailand

${ }^{3}$ Thai Association of Gastrointestinal Endoscopy, Thailand

${ }^{4}$ Screening Group, International Agency for Research on Cancer, Lyon, France ${ }^{5}$ International Agency for Research on Cancer, Lyon, France

Acknowledgements The authors gratefully acknowledge the assistance provided by the public health authorities in Lampang province, staff of the Lampang province public health services, particularly the nurses and health workers in the primary care units and community hospitals and staff of the Lampang Provincial Hospital, Lampang Regional Cancer Center and the population-based cancer registry of Lampang province for the various components of this pilot project. The authors would specifically like to thank Dr Sirichai Pathranuthaporn and Mr Kitti Sriarwatchanakarn for their kind coordination of services from all healthcare facilities in Lampang province in the context of the pilot project. The assistance provided by Mrs Evelyn Bayle, Ms Sandrine Montigny and Mrs Krittika Guinot in the preparation of this manuscript is gratefully acknowledged.

Contributors All the authors involved in the conception and design, interpretation of data, revising the article critically for important intellectual content and final approval of the version to be published.

Funding The project was funded by the Ministry of Public Health, Thailand, through the National Cancer Institute (NCI), Bangkok, Thailand. 
Competing interests None.

Ethics approval Ethical approval was obtained from Institutional Review Board and Ethics Committee of $\mathrm{NCl}$ and the International Agency for Research on Cancer (IARC)

Provenance and peer review Not commissioned; externally peer reviewed.

Data sharing statement No additional data are available.

Open Access This is an Open Access article distributed in accordance with the Creative Commons Attribution Non Commercial (CC BY-NC 3.0) license, which permits others to distribute, remix, adapt, build upon this work noncommercially, and license their derivative works on different terms, provided the original work is properly cited and the use is non-commercial. See: http:// creativecommons.org/licenses/by-nc/3.0/

\section{REFERENCES}

1. Khuhaprema $\mathrm{T}$, Attasara $\mathrm{P}$, Sriplung $\mathrm{H}$, et al. Cancer in Thailand Volume VI, 2004-2006. Bangkok: NCIB, 2012.

2. Gryfe R, Swallow C, Bapat B, et al. Molecular biology of colorectal cancer. Curr Probl Cancer 1997;21:233-300.

3. Levin B, Lieberman DA, Mc Farland B, et al. Screening and surveillance for the early detection of colorectal cancer and adenomatous polyps, 2008: a joint guideline from the American Cancer Society, the US Multi-Society Task Force on Colorectal Cancer, and the American College of Radiology. CA Cancer J Clin 2008:58:130-60.

4. Hewitson P, Glasziou P, Irwig L, et al. Screening for colorectal cancer using the faecal occult blood test, Hemoccult. Cochrane Database Syst Rev 2007;(2):CD001216.

5. Ouyang DL, Chen JJ, Getzenberg RH, et al. Noninvasive testing for colorectal cancer: a review. Am J Gastroenterol 2005;100:1393-403.

6. Burch JA, Soares-Weiser K, St John DJ, et al. Diagnostic accuracy of faecal occult blood tests used in screening for colorectal cancer: a systematic review. J Med Screen 2007;14:132-7.

7. van Rossum LG, van Rijn AF, Laheij RJ, et al. Random comparison of guaiac and immunochemical fecal occult blood tests for colorectal cancer in a screening population. Gastroenterology 2008;135:82-90.

8. Rabeneck L, Rumble RB, Thompson F, et al. Fecal immunochemical tests compared with guaiac fecal occult blood tests for population-based colorectal cancer screening. Can J Gastroenterol 2012;26:131-47.

9. Sewitch MJ, Fournier C, Ciampi A, et al. Colorectal cancer screening in Canada: results of a national survey. Chronic Dis Can 2008;29:9-21.

10. Sigurdsson JA, Getz L, Sjonell G, et al. Marginal public health gain of screening for colorectal cancer: modelling study, based on WHO and national databases in the Nordic countries. J Eval Clin Pract 2013:19:400-7.

11. Shim JI, Kim Y, Han MA, et al. Results of colorectal cancer screening of the National Cancer Screening Program in Korea, 2008. Cancer Res Treat 2010:42:191-8.

12. Saito $\mathrm{H}$. Colorectal cancer screening using immunochemical faecal occult blood testing in Japan. J Med Screen 2006;13(Suppl 1):S6-7.

13. Hanvoravongchai P. UNICO Study Series 20 . Health financing reform in Thailand: toward Universal coverage under fiscal constraints. Washington, District of Columbia: World Bank, 2013.

14. Forman D, Bray F, Brewster DH, et al. Cancer incidence in five continents, Vol. X (electronic version). Lyon: IARC. http://ci5.iarc.fr (accessed 30 Nov 2013)

15. Shin A, Jung KW, Won YJ. Colorectal cancer mortality in Hong Kong of China, Japan, South Korea, and Singapore. World J Gastroenterol 2013;19:979-83.

16. Bosetti C, Levi F, Rosato V, et al. Recent trends in colorectal cancer mortality in Europe. Int J Cancer 2011;129:180-91.

17. Jemal A, Siegel R, Xu J, et al. Cancer statistics, 2010. CA Cancer J Clin 2010;60:277-300.

18. UK Colorectal Cancer Screening Pilot Group. Results of the first round of a demonstration pilot of screening for colorectal cancer in the United Kingdom. BMJ 2004;329:133.
19. Steele RJ, McClements PL, Libby G, et al. Results from the first three rounds of the Scottish demonstration pilot of FOBT screening for colorectal cancer. Gut 2009;58:530-5.

20. Malila N, Oivanen T, Hakama M. Implementation of colorectal cancer screening in Finland: experiences from the first three years of a public health programme. $Z$ Gastroenterol 2008;46(Suppl 1): S25-8.

21. Commonwealth of Australia. The Australian Bowel Cancer Screening Pilot Program and Beyond, 2005. Screening monograph no.6/2005. 2005. http://www.health.gov.au/internet/screening/publishing.nsf/ Content/2DDFA95B20302107CA257 (accessed 30 Nov 2013)

22. Denis B, Ruetsch M, Strentz P, et al. Short term outcomes of the first round of a pilot colorectal cancer screening programme with guaiac based faecal occult blood test. Gut 2007;56:1579-84.

23. von Wanger C, Baio G, Raine R, et al. Inequalities in participation in an organized national colorectal cancer screening programme: results from the first 2.6 million invitations in England. Int J Epidemiol 2011;40:712-18.

24. Australian Institute of Health and Welfare. National Bowel Cancer Screening Program monitoring report: July 2011-June 2012. Cancer series no. 75 Cat. no. CAN 71. 2013. http://www. aihw.gov.au/ publication-detail/?id=60129543900 (accessed 30 Nov 2013)

25. Park MJ, Choi KS, Jun JK, et al. Trends in the National Cancer Screening Program for colorectal cancer in the Republic of Korea, 2004-2009. Asian Pac J Cancer Prev 2011;12:3489-93.

26. Khalid-de BC, Jonkers D, Smits K, et al. Participation in colorectal cancer screening trials after first-time invitation: a systematic review. Endoscopy 2011:43:1059-86.

27. Moss SM, Campbell C, Melia J, et al. Performance measures in three rounds of the English bowel cancer screening pilot. Gut 2012;61:101-7.

28. Van Hal G, Hoeck S, Van Roobroeck S. Screening for colorectal cancer: sense and sensibilities. Eur J Cancer 2011;47(Suppl 3): S156-63.

29. Malaga LA, Salas TD, Sala FT, et al. [Programme of screening for colorrectal cancer in the Valencia community, Spain: results of the first round (2005-2008)]. Rev Esp Salud Publica 2010; 84:731-43.

30. Grazzini G, Castiglione G, Ciabattoni C, et al. Colorectal cancer screening programme by faecal occult blood test in Tuscany: first round results. Eur J Cancer Prev 2004;13:19-26.

31. Parente F, Boemo C, Ardizzoia A, et al. Outcomes and cost evaluation of the first two rounds of a colorectal cancer screening program based on immunochemical fecal occult blood test in northern Italy. Endoscopy 2013;45:27-34.

32. Katicic M, Antoljak N, Kujundzic M, et al. Results of National Colorectal Cancer Screening Program in Croatia (2007-2011). World $J$ Gastroenterol 2012;18:4300-7.

33. Morris $\mathrm{S}$, Baio G, Kendall $\mathrm{E}$, et al. Socioeconomic variation in uptake of colonoscopy following a positive faecal occult blood test result: a retrospective analysis of the NHS Bowel Cancer Screening Programme. Br J Cancer 2012;107:765-71.

34. Rutter CM, Johnson E, Miglioretti DL, et al. Adverse events after screening and follow-up colonoscopy. Cancer Causes Control 2012;23:289-96.

35. Thomas-Gibson $\mathrm{S}$, Bassett $\mathrm{P}$, Suzuki $\mathrm{N}$, et al. Intensive training over 5 days improves colonoscopy skills long-term. Endoscopy 2007;39:818-24.

36. Curado MP, Edwards B, Shin HR, et al. Cancer incidence in five continents Vol IX. IARC Scientific Publications No. 160. Lyon: IARC, 2007.

37. Winawer SJ, Zauber AG. The advanced adenoma as the primary target of screening. Gastrointest Endosc Clin N Am 2002;12:1-9, v.

38. Brenner $\mathrm{H}$, Hoffmeister M, Stegmaier $\mathrm{C}$, et al. Risk of progression of advanced adenomas to colorectal cancer by age and sex: estimates based on 840,149 screening colonoscopies. Gut 2007:56:1585-9.

39. Australian Government. Department of Health. National Bowel Cancer Screening Program. http://www.cancerscreening.gov.au/ internet/screening/publishing.nsf/Content/bowel-about (accessed 30 Nov 2013)

40. Bray F, Jemal A, Grey N, et al. Global cancer transitions according to the Human Development Index (2008-2030): a population-based study. Lancet Oncol 2012;13:790-801. 